\title{
Horizontes de expectativas. Centroamérica en el bosque de la modernidad
}

\author{
Manuel Burón DíAZ \\ CCHS-CSIC \\ manuel.buron@cchs.csic.es
}

Según Reinhart Koselleck la conciencia moderna del tiempo se caracterizó por la creciente diferencia entre el espacio de experiencia y el horizonte de expectativas ${ }^{1}$. John G. A. Pocock denominó tiempo profano o secular a aquel que, renunciando a la búsqueda del horizonte escatológico de la salvación cristiana, dejaba en manos del hombre la creación de un mundo racional ${ }^{2}$. Ambas visiones contemplan el nacimiento de la edad moderna en su mirada hacia el futuro, esto es, deshaciéndose despectivamente de su bagaje medieval, escolástico y campesino. Como la historia del pensamiento político tiende a convertirse en una historia de las mutaciones de los presupuestos esenciales en los que se basaba (como nos explica Pocock) una historia de los conceptos claves de la modernidad, como la que aquí se analiza, ha de atender al análisis de dichos cambios, presupuestos que son rebatidos para hacer nacer un nuevo contexto.

A esta misión se encomendó una disciplina histórica que se adentraba en un periodo de fértil confusión, sucediéndose etiquetas de todo tipo que intentaron diferenciar la historia del pensamiento, de las ideas, intelectual, de las mentalidades, de los conceptos, de la palabra o historia del discurso. Bajo este frenesí conceptual subyacía el intento de conciliar la irresoluble tensión entre realidad y pensamiento, reformulada en la dicotomía que enfrentó a Weber y Marx por la primacía entre ideología y economía. Frente a una historia de las ideas y de los conceptos, surgía con el giro lingüístico una mayor atención al contexto, menor al autor, y a diferentes concepciones que explicaban la trascendencia del lenguaje en su cualidad performativa (Foucault) o como simple acción que se enuncia, que se verbaliza (Skinner y Pocock). Los derroteros tradicionalmente separados, cuando no opuestos, por los que discurrían realidad e ideología convergían, por fin, en un todo único e indisociable, en el que las ideas eran consideradas como

actos de expresión inmediata de un contexto concreto para el que la realidad se encuentra directamente condicionada por una reflexión que al estar completamente pegada e incorporada a ella, es operativa como un hecho más de lo que los hombres piensan en el ámbito de lo cotidiano ${ }^{3}$.

1 Citado en Habermas, 2008, p. 22.

2 Pососк, 2002, p. 77 y s.

3 García, 2002, p. 20. Lenguaje y realidad forman un todo, pero Koselleck (2004) nos advierte que "la propia realidad no se deja reducir a su significado y forma lingüística (...) Esta determinación diferencial implica además, que cada concepto tiene una historia. Precisamente porque cada palabra puede tener una multiplicidad de significados que se van adecuando a la realidad mudable". 
La publicación de dos obras - una colectiva, coordinada por Marta Casaús Arzú, que lleva el significativo nombre de El lenguaje de los ismos, dado su enfoque a caballo entre la historia de los conceptos y de las ideas políticas en América Latina; y una recopilación de artículos del mencionado J. G. A. Pocock- nos ofrece una excusa para reflexionar acerca de la compleja relación que mantienen filosofía, historia y política, en un espacio supuestamente periférico como el de Centroamérica. Con el aliciente de que estas visiones de los cambios políticos, de esos "momentos" en los que el tiempo parece estar "fuera de sus goznes", según la conocida frase shakesperiana, nos suele indicar un propio "presente desgarrado". Así sucedió cuando el conocido libro de John Rawls, Tratado de la justicia ${ }^{4}$ — de un idealismo inmovilista muy al uso en las últimas décadas - fue contestado por Pocock con su gran obra, el Momento maquiavélico ${ }^{5}$. Ambas suponían una reacción a la realidad estadounidense y al giro ideológico que sucedía en los años setenta, cuyos resultados más agresivos estamos sufriendo en el "momento" actual.

Es precisamente esta (deseada o denostada) carga "performativa" que se supone inherente a los "ismos", lo que les ha reservado un lugar de honor en la historia de los conceptos. Primero, el sufijo ismo ha supuesto la modernidad, en el sentido más histórico de tan oscura palabra ${ }^{6}$. Desde el "patriotismo", considerado el primero en aparecer allá por los albores del siglo XVIII, hasta aquel que, a pesar de haber desencadenado una de las mayores tormentas de conceptos de la contemporaneidad, nunca pudo verse realizado: el "comunismo". La cuestión de la modernidad es importante si reparamos en la obstinada negación historiográfica de la misma que ha sufrido el mundo hispánico en general, y Centroamérica en particular. Esta región tachada comúnmente de "área periférica y dependiente" es, sin embargo, el centro donde gravita la obra que aquí nos ocupa; enfoque necesariamente subversivo, pues es conocido cómo la modernidad americana fue puesta a la sombra del gran árbol moderno por antonomasia: políticamente ideado en Francia y económicamente fabricado en Inglaterra. El propio término de Sattelzeit ideado por Reinhart Koselleck, algo así como "tiempo bisagra", se refiere casi en exclusiva al mundo germano entre 1750 y 1850. En segundo lugar, el interés de los "ismos" reside en su estructura temporal interna, en su bagaje de significados pasados, pero sobre todo, en su afán de expectativas de futuro. En palabras del mismo Koselleck, en su "potencial dinámico y de transformación, temporalmente generado, por así decirlo, dentro del lenguaje" ${ }^{\text {. }}$. Son conceptos generadores de innovación, por un lado, pero por otro circunscriben ideológicamente -ideopraxis las denominó Lucien Jaume ${ }^{8}$ - una serie de anhelos forjados en una reali-

4 RAWLS, 1979.

5 Pocock, 2002.

6 Para un estudio histórico del concepto de "modernidad" en política véase KoselLeck, 1993, o QuiJadA, 2008, pp. 19-52. En esta nota subrayo, y añado a la polisemia atribuida a la "modernidad", pero también a la ilustración, la importancia de su configuración "frente a la escolástica", en tanto clerical o tradicionalista. Pero sin negar una influencia necesaria y evidente de esta última en la genealogía de las características que se le suponen a la primera. Tales como la invención del individuo su asociación "voluntaria" en un conjunto que constituye el "pueblo o nación, la soberanía popular, etc".

7 Koselleck, 2004, p. 38.

8 "He propuesto denominar ideopraxias a estos conjuntos estables (como, por ejemplo, el liberalismo francés del siglo XIX) para subrayar la importancia de las condiciones de materizalización "práctica" del pensamiento político". En JAUME, 2006, p. 193. 
dad específica de la que es imposible separar si se quiere comprender correctamente. Acotan una serie de significados, demarcando un sistema de ideas, que intenta dar respuestas a una situación concreta. En esta encrucijada entre dinamismo y circunscripción, entre lenguaje y realidad, a través de la historia, reside la dificultad de su estudio.

Marta Elena Casaús, coordinadora del volumen que centra este análisis, aborda tan complicada tarea a través de la colaboración de grandes especialistas. Mónica Quijada es una investigadora con larga tradición en el estudio de imaginarios políticos y posee tan agudo pensamiento que ella misma ha creado conceptos clave para el estudio de la historia política. Su concepto de "invisibilización" referido al indígena en la historia argentina en específico, ha abierto no pocas puertas, y no siempre suficientemente reconocidas, a nuevas investigaciones. En este volumen, sin embargo, realiza una disección del término "pueblo" dentro del reconocimiento de la importancia del municipio como poder intermedio en la consecución de la modernidad hispánica, para averiguar quiénes eran aquellos actores sociales que llenaron de contenido dichos procesos políticos, y cómo se generó y mutó el sentido de dicho concepto, hasta elevarse en uno de los pilares de la modernidad. Tal como ya hiciera con la "nación" en anteriores y recordadas obras ${ }^{9}$, Quijada realiza una necesaria "genealogía" del término "pueblo" ante el indiscriminado uso político con el paso del tiempo, y ante el pretendido monopolio que hace del mismo el mundo anglosajón.

También es especialmente revelador de la utilidad de la historia de los conceptos el artículo de Elías José Palti. En él se trata de clarificar la coexistencia, aparentemente contradictoria, de reivindicación y crítica de la democracia en los textos de principios del siglo XIX. Lo que muchos historiadores tacharon de prejuicios tradicionalistas antidemocráticos, Palti lo achaca a la misma naturaleza ambigua y elusiva de la democracia, tocada por la antinomia formada entre los fundamentos del poder (la ideología democrática) y las formas efectivas de su ejercicio (la praxis democrática).

Pero más interesante que la clarificación de esa errónea visión histórica es lo que se deriva de la misma. A saber, el actual abandono de la crítica de la idea de democracia, y la ignorancia de su propia naturaleza dilemática. En otras palabras, las contradicciones entre los autores de principios del XIX, y la propia presencia de "ismos", implicaba un debate que hoy día desapareció ante el blindaje de la idea de democracia, cuyo abordaje crítico implica ser tachado de autoritario o anti-sistema. Hoy, la democracia carece de una mínima actividad conceptual y, a diferencia del siglo XIX, no posee un "ismo" generador de innovaciones, sino que se ha esclerotizado por evidentes razones históricas que la han convertido en uno de los pilares políticos de la actualidad, en eso que llamó Koselleck un "concepto ideologizable" (ideologisierbar) y por tanto deviene en un abstracto "singular colectivo" de significados demasiado difusos. La historia de los conceptos ha subrayado con frecuencia el conflictivo hecho de que los conceptos permanezcan invariables mientras la realidad cambia rápidamente. El ejemplo tradicional propuesto para ilustrar este conflicto siempre fue la insoportable contradicción entre realidad y principios progresivamente acumulada en el bloque

9 Quijada, 1994, pp. 15-52. 
socialista durante la guerra fría. Explícitamente señalado por Koselleck ${ }^{10}$ y en el estudio preliminar de la edición española de El momento maquiavélico de Pocock ${ }^{11}$, se aducía que fue precisamente esta creciente diferencia entre realidad y discurso lo que precipitó la caída de la URSS, explicitada en la conocida frase de Rudi Dutschke: "al este del Elba todo era real menos el socialismo". Pues bien, lo mismo cabría decir, hoy por hoy, —otro tiempo "acelerado" digno del estudio de un futuro Koselleckdel alejamiento de una realidad cada día más extrañada de los principios informadores de la legitimidad constitucional-democrática.

De ahí la visión presentista de todos aquellos historiadores que vieron, en las razonables dudas decimonónicas acerca de la propia estructura de la democracia, un rancio prejuicio tradicionalista de las élites latinoamericanas. En similares coordenadas se mueve el artículo de Stuven acerca de las diferencias doctrinarias entre el republicanismo liberal y el conservador, donde las simplificaciones historiográficas a menudo han dibujado polaridades ideológicas donde en realidad no las había. Como se puede ver, todos los artículos señalados hasta el momento logran renovar, a la manera de Gadamer, esa "tensión del pensar" en la que se despliega el ánimo del concepto.

Los artículos elaborados por María del Rosario Peludo y por Artemis Torres abordan la influencia del positivismo en México y Guatemala, desde el estudio de libros de texto y artículos periodísticos, respectivamente. Es bien sabido que las corrientes políticas, y con ellas, los conceptos, se despliegan dialécticamente frente a sus predecesores. El hecho de analizarlos en el "tiempo donde se cultivaron", recurriendo a los textos decimonónicos, pero desprendiéndolos de la matriz que los generó, puede llevar precisamente a una minusvaloración de dichos momentos anteriores frente a los que se despliegan; de ahí la importancia de textos como el de Mónica Quijada que rompen el cierre historiográfico impuesto entre periodos para precisamente lograr un correcto entendimiento del deslizamiento semántico de dicho concepto en la "larga duración". De la misma manera que los conceptos artístico-temporales se sucedían unos a otros, denostando lo anterior, incluso adquiriendo un carácter peyorativo como sucede con el "impresionismo", "fauvismo" o el propio periodo "gótico"—no es casualidad que Hegel el principal enunciador de la dialéctica histórica fuera también el primero en hablar de Begriffsgeshichte, de historia de los conceptos-, del mismo modo, decimos, los movimientos políticos se definen arramblando con lo inmediatamente anterior. De esta manera, la dinámica progresista de la ilustración o el positivismo se opuso a la "estática" y "conservadurismo" de la "filosofía escolástica" colonial. Pero sin atender a la segunda es imposible aprehender correctamente la primera. La historia de los conceptos nace contra los anacronismos, para recuperar el significado de los términos políticos de cada época, despojándolos de toda la carga de significados incorporados con el paso del tiempo, conectándolos así con su contexto político y social. Pero ese contexto está caracterizado por el bagaje de otros significados de los que se intenta librar. Es un contexto nuevo porque se identifica intentando diferenciarse de lo anterior. Las metáforas dadas como zeitgeist o "superestructura" —más que el "momento" de Pocock o el Sattelzeit de Koselleck, de carácter más

10 Koselleck, 2004, p. 32.

11 García, 2002, p. 54. 
procesual- indican un estado de las cosas ya interiorizado por toda la sociedad. De ahí la importancia de conocer la acción anterior y no sólo la reacción posterior, los dos lados de la bisagra de Koselleck o de los goznes de Shakespeare. Se podría argumentar lo absurdo de la necesidad de establecer una "genealogía" infinita para comprender dicho proceso en su plenitud, pero lo cierto es que de las dos lecturas de Peludo y Torres -y más concretamente del despliegue filosófico sobre el que se sustenta el liberalismo y positivismo, tomado por dichos autores de Leopoldo Zea-, nos aparece una visión deformada de la filosofía escolástica, como contraria a la modernidad y no como posible generadora de la misma, precisamente, por el impulso que de ella toman las filosofias posteriores, sin tener en cuenta la decisiva influencia (y formación) escolástica que tuvieron personajes tan fundamentales para la modernidad como Descartes, Leibniz, Spinoza, Kant, incluso Heidegger.

En otras palabras, entenderemos perfectamente el contexto en que se formaron dichos movimientos, su justificación y aplicación, pero solo conoceremos el resultado de la explosión de significados y conceptos, no los elementos anteriores cuya mezcla provocaría tal reacción. Así, paradójicamente, caeríamos en la misma apasionada actitud "presentista" hacia el periodo anterior que poseían, por ejemplo, los diputados americanos del siglo XIX o incluso el propio Leopoldo Zea ${ }^{12}$. Cometeríamos el error, parodiando el título de la obra de Koselleck, de situarnos en aquel "presente pasado". El mismo Pocock ya se refirió a ello cuando elaboró su concepto clave de speech act para referirse, precisamente, a la relectura que los humanistas hicieron del pensamiento clásico por pura oposición a la lectura anteriormente realizada por la filosofía escolástica.

De esta manera los "ismos" deben ser contemplados como generadores de innovación, pero esa generación no es espontánea, no adolecen de una causa sui circunscrita al periodo que la hizo posible. El historiador de los conceptos no debe detenerse en un mero "contextualismo" lingüístico, pues posee una visión de la historia que le permite la contemplación de los diferentes "despliegues" de los conceptos, los marcos económicos y políticos que los generaron y las variaciones semánticas que han sufrido con el tiempo. En este rompimiento de constructos historiográficos, cierres temporales y condicionamientos históricos debería incidir una historia de los conceptos que presentara el deslizamiento semántico de los conceptos no como "cápsulas" ceñidas en las visiones sesgadas de cada periodo, ni como una continuación escalonada de "instrumentos de orden mental"13 en palabras de Zea, no como esos "túneles de la revolución" que partían del centro de la mina que era París, según Víctor Hugo ${ }^{14}$; ni siquiera como esquemas arborescentes o líneas genealógicas más o menos definidas, sino más bien, si se permite la metáfora, como un bosque entero de árboles genealógi-

12 Actitud presentista que siempre tiene un impulso material que es necesario analizar. Ya sea el afán de diferenciarse de España de los diputados americanos, o la liberación de América Latina del neocolonialismo estadounidense de Leopoldo Zea. Exactamente del mismo modo que Kant idolatró canónicamente la ilustración en su afán de adular a Federico de Prusia, o el propio de Pio IX al defender a la Iglesia con su feroz crítica a la modernidad, por poner dos ejemplos conocidos. En lo que respecta a la historiografía americana no hay más que recordar a Borges cuando afirmaba que "nuestra historia comienza por ser toda ella una tentativa de diferenciación a partir del tronco hispánico", citado en QuIJADA, 2008, p. 19.

13 ZEA, 1974, p. 62.

14 Citado en Hobsbawm, 2001, p. 311. 
cos, de diferente vigor e influencia -europeo, francés, hispano, centroamericano...donde es necesario estudiar en cada uno de ellos y en conjunto, tanto la semilla y la raíz como el vistoso conjunto que resulta ${ }^{15}$.

En mi opinión, tampoco se deberían contemplar las líneas de estos discursos, por muy interrelacionadas o fluidas que se describan, como capaces de ser destruidas, quebradas, rotas, para alumbrar un discurso, un bosque conceptual nuevo, más o menos como propuso Pocock siguiendo a Kuhn. La metáfora del bosque nos permite contemplar cada elemento formando una línea o conjunto de líneas genealógicas conceptuales, en interacción o independencia con cualquier otro, pero formando un complejo sistema histórico. Ni holista, ni pluralista. Sin la necesidad de "pisos" paradigmáticos que se sustituyen unos a otros en base a bruscos incendios que destruyan (o "invisibilicen") todo lo anterior, y, por tanto, sin subyugar todo lenguaje y concepto a un único centro generador de ramificaciones secundarias.

Este punto de vista parece útil si atendemos a nuestro caso de estudio en el libro de Casaús, que indaga en definitiva en la aparición de "ismos" en la región centroamericana en su conexión con otras realidades. Existen otros muchos magníficos artículos en dicho volumen, comenzando por el de su propia coordinadora, a raíz de la fundamental evolución del binomio degeneración-regeneración en Guatemala, o los de Teresa García Giráldez acerca del "unionismo y el imperialismo", réplica centroamericana, este último, del fundamental estudio de Koebner. Todos ellos en conjunto dibujan el periodo tratado en la obra como un genuino Sattelzeit centroamericano, con una fecunda proliferación de "ismos", como una metafórica "aceleración" —como diría Koselleck-, que refleja un ansia de expectativas en la zona en el surgimiento de nuevos conceptos y significados. Y por tanto es capaz de mostrarnos, a la manera de Pocock, la actividad de los hombres y mujeres frente a la realidad contingente, sobre el tiempo y el espacio que les es propio, sobre la condición de posibilidad que es la política, y sobre el uso y manipulación que exhibieron de todo concepto, experiencia, acontecimiento o lenguaje. La simple exposición histórica de esa "condición de posibilidad" se proyecta casi de manera subversiva sobre nuestro presente.

Así, la supuesta cualidad de "área periférica", su carácter social pluriétnico y su profunda multiculturalidad, manifiesta la singularidad de la región centroamericana, pero sin implicar un aislamiento absoluto ni tampoco una dependencia radical. Al contrario, las numerosas y fecundas ramificaciones de la intelectualidad centroamericana que percibimos en la gran obra de Casaús, con su brillo particular, con sus rasgos singulares, produjeron una gran cantidad de racimos conceptuales, que forman parte sustancial del prolífico bosque de la modernidad.

\section{REFERENCIAS BIBLIOGRÁFICAS}

CAsaús Arzú, Marta Elena (coord.)

2010 El lenguaje de los ismos: algunos conceptos de la modernidad en América Latina. Guatemala. F\&G Editores.

15 Un conjunto que sin duda alguna podemos calificar de euroamericano, véase LEMPÉRIÉRE, 2004, p. 397-418. 
GADAMER, Hans Georg

1972 "Begriffsgeschichte als Philosophie". Kleine Schriften III, Idee und Sprache. Tübingen. pp. 237-244.

GARCía, Eloy

2002 “Estudio preliminar". En Poсоск, J. G. A., El momento maquiavélico. El pensamiento político florentino y la tradición republicana atlántica. Madrid. Ed. Tecnos.

HaBERMAS, Jürgen

2008 EL discurso filosófico de la modernidad. Buenos Aires. Ed. Katz.

HoBSBAwM, Eric

2001 La era de la revolución 1789-1848. Barcelona. Ed. Crítica.

JAUME, Lucien

2006 "Reflexión sobre el sentido y la ideología en los textos de intervención política. El caso Fiévée en 1815". Revista de Estudios Políticos (nueva época). Madrid, nº 134, pp. 177-193.

KOSELLECK, Reinhart

1993 Futuro pasado. Para una semántica de los tiempos históricos. Barcelona. Ed. Paidós.

2004 "Historia de los conceptos y conceptos de historia". Revista Ayer. Madrid, $\mathrm{n}^{\mathrm{o}} 53$, pp. $27-45$.

LEMPÉRIÉRE, Annick

2004 "La construcción de una visión euroamericana de la historia". En PANI Salmerón (eds.), Conceptualizar lo que se ve. François-Xavier Guerra, historiador. Homenaje. México. Instituto Mora, pp. 397-418.

Pocock, John Greville Agard

2002a El momento maquiavélico. El pensamiento político florentino y la tradición republicana atlántica. Madrid. Ed. Tecnos.

2002b Historia e Ilustración. Doce estudios. Madrid. Marcial Pons.

2012 Pensamiento político e historia. Ensayos sobre teoría y método. Madrid. Ed. Akal.

QuiJADA, Mónica

1994 “Qué nación? Dinámicas y dicotomías de la nación en el imaginario hispanoamericano del siglo XIX”, en Guerra - QuiJADA (coords.), Cuadernos de AHILA, no 2, pp. 15-52.

2008 "Sobre nación, pueblo, soberanía y otros ejes de la modernidad en el mundo hispano", en RodríGuEz (coord.), La nuevas naciones: España y México, 1800-1850. Madrid. Instituto de Cultura - Fundación Mapfre, pp. 19-52.

RawLS, John

1979 Teoría de la justicia. México. FCE.

ZEA, Leopoldo

1976 El pensamiento latinoamericano. Barcelona. Ed. Ariel. 